\title{
Preparation and Characterization of Silver Nanoparticles and Their Use in Catalytic Reduction of 4-Nitrophenol
}

\author{
F. A. Al-Marhaby' ${ }^{1}$ R. Seoudi 2,3 \\ ${ }^{1}$ Department of Physics, University College in Qunfudah, Umm Al-Qura University, Makkah, KSA \\ ${ }^{2}$ Spectroscopy Department, Physics Division, NRC, Dokki, Cairo, Egypt \\ ${ }^{3}$ Department of Physics, College of Applied Science, Umm Al-Qura University, Makkah, KSA \\ Email: rsmawed@yahoo.com, shabeeh-alward@hotmail.com
}

Received 13 December 2015; accepted 29 February 2016; published 4 March 2016

Copyright (C) 2016 by authors and Scientific Research Publishing Inc.

This work is licensed under the Creative Commons Attribution International License (CC BY). http://creativecommons.org/licenses/by/4.0/

c) (7) Open Access

\begin{abstract}
Silver nanoparticles of various sizes were prepared at room temperature using silver nitrate as a precursor, various molar ratios of sodium citrate as a surfactant stabilizing material and sodium borohydride as a reducing agent. The morphology, distribution and sphericity of the particles were assessed in images from a transmission electron microscope (TEM). The sizes of the particles were calculated as being 9,11 and $14 \mathrm{~nm}$. The effects of the particles' sizes on the plasmon bands were confirmed by ultraviolet-visible spectra measurements. The prepared samples were applied in photo catalysis of 4-Nitrophenol (4-NP), and the rate constant was determined as $0.05 \mathrm{~s}^{-1}$, $0.0015 \mathrm{~s}^{-1}$ and $0.00021 \mathrm{~s}^{-1}$ for particles of $9 \mathrm{~nm}, 11 \mathrm{~nm}$ and $14 \mathrm{~nm}$, respectively. Due to their high surface energy, the smaller particle sizes were more active in the photo catalytic application.
\end{abstract}

\section{Keywords}

Silver Nanoparticles, Surface Plasmon Band, Photocatalyst, Rate Constant

\section{Introduction}

A nanoparticle is the most fundamental component in the fabrication of a nanostructure. A nanoparticle is bigger than an atom or a simple molecule that is governed by quantum mechanics [1]. Nanoparticle shaves unique properties, especially optical, electronic and biological properties [2]-[5]. Due to their high surface-to-volume ratio, nanoparticles can be used in heterogeneous catalysis [6] [7]. In addition, they are applied in many fields, including photonics, micro-electronics, lithography and surface-enhanced Raman spectroscopy [8] [9]. As noble 
metal nanoparticles, silver nanoparticles show unique chemical and physical properties. They have excellent conductivity, chemical stability and catalytic activity. These properties are directly dependent on their size, size distribution and shape [10]-[12]. In addition, silver materials with one- and two-dimensional nanostructures, including nanowires and nanocubes, are believed to have great potential applications [13]-[16]. Silver nanoparticles (AgNPs) can be prepared using physical methods that include evaporation-condensation and laser ablation. In particular, these two methods are used to prepare AgNPs in the form of thin films [17]. However, laser ablation can be used to synthesize AgNPs in solution [18]. In addition, AgNPs can be prepared by chemical reduction, such as microemulsion techniques [19], UV-initiated photo reduction [20], photo induced reduction [21], electrochemical synthetic methods [22], irradiation methods [23] and microwave-assisted synthesis [24]. In a biosynthesis method, AgNPs have been synthesized using bacteria [25], fungi [26], algae [27] and plants [28] [29].

Although 4-nitrophenol (4-NP) is a class of pollutant, stable in the environment and resistant to biodegradation [30] [31], it can be transformed to safety compound 4-aminophenol (4-AP) by using AgNPs due to their catalytic properties. The aim of the present work is to synthesize various sizes of spherical AgNPs using trisodium citrate as a surfactant material. The particle sizes and plasmon bands were assessed using Transmission Electron Microscope (TEM) images and ultraviolet-visible (UV-VIS) spectra. The results clarified the effect of particle size on the reduction conversion of 4-NP to 4-AP using sodium borohydride $\left(\mathrm{NaBH}_{4}\right)$ as a model reaction.

\section{Experimental}

\subsection{Chemicals}

Silver nitrate $\left(\mathrm{AgNO}_{3} \geq 99.99 \%\right)$ with a molecular weight of $169.87 \mathrm{~g} / \mathrm{mol}$, trisodium citrate $\left(\mathrm{Na}_{3} \mathrm{C}_{6} \mathrm{H}_{9} \mathrm{O}_{9} \geq 99 \%\right)$ with a molecular weight of $258.06 \mathrm{~g} / \mathrm{mol}$ and sodium borohydride $\left(\mathrm{NaBH}_{4} \geq 99.99 \%\right)$ with a molecular weight of $37.83 \mathrm{~g} / \mathrm{mol}$ were purchased from Sigma-Aldrich (Steinheim, Germany). 4-NP was purchased from SigmaAldrich (USA) and used as received without further purification. Distilled, deionized water was used throughout the experiments.

\subsection{Preparation of Colloidal AgNPs by the Chemical Method}

Stock solutions of silver nitrate with a concentration of metal salt $\left(\mathrm{AgNO}_{3}, 2.5 \times 10^{-4} \mathrm{M}\right)$ and trisodium citrate dihydrate $\left(\mathrm{HOC}(\mathrm{COONa})\left(\mathrm{CH}_{2} \mathrm{COONa}\right)_{2} \cdot 2 \mathrm{H}_{2} \mathrm{O}, 2.5 \times 10^{-4} \mathrm{M}\right)$ were prepared in a conical flask and stored in the dark to protect against light. Next, $0.1 \mathrm{M}$ of ice-cold $\mathrm{NaBH}_{4}$ was prepared as a stock solution. To prepare Sample 1 (S1), $5 \mathrm{~mL}$ of $2.5 \times 10^{-4} \mathrm{M}$ trisodium citrate dihydrate was mixed with $20 \mathrm{~mL}$ of $2.5 \times 10^{-4} \mathrm{M} \mathrm{AgNO}_{3}$ solution under magnetic stirring for $10 \mathrm{~min}$ at room temperature before $0.6 \mathrm{~mL}$ of ice-cold $\mathrm{NaBH}_{4}$ was added. The colour of the mixture quickly changed to yellow, indicating the formation of AgNPs. Sample 2 (S2) and Sample 3 (S3) were prepared by the same method except that the molar ratio of trisodium citrate dehydrate was changed by adding 20 and $40 \mathrm{~mL}$ of $\mathrm{HOC}(\mathrm{COONa})\left(\mathrm{CH}_{2} \mathrm{COONa}\right)_{2} \cdot 2 \mathrm{H}_{2} \mathrm{O}$ to $20 \mathrm{~mL}$ of $\mathrm{AgNO}_{3}$ for S2 and S3, respectively.

\subsection{Characterization}

The morphology and distribution of the AgNPs samples were analysed using TEM images. The TEM (JEOLJEM-1011; Japan) was operated at an accelerating voltage of $120 \mathrm{kV}$. The TEM samples were prepared by depositing one drop of colloidal AgNPs on a carbon-coated standard copper grid (300 mesh) and allowing it to dry before making the TEM measurements. The UV-VIS absorption spectra of the AgNPs were measured at room temperature on a spectrophotometer (Thermo-scientific Evolution 220) in a 1-cm optical path quartz cuvette over a 350 - 700-nm wavelength at a resolution of $2 \mathrm{~nm}$.

\subsection{Photo-Catalytic Reduction of 4-NP Using $\mathrm{NaBH}_{4}$ and Colloidal AgNPs}

The photo-catalytic reduction of 4-NP was performed in a quartz cuvette $4 \mathrm{~cm}$ high and with a 1-cm optical path length. An aqueous solution of $0.03 \mathrm{M}$ of $\mathrm{NaBH}_{4}$ and $2 \mathrm{mmol}$ of $4-\mathrm{NP}$ was prepared and stored at $4{ }^{\circ} \mathrm{C}$. The photo-catalytic reduction was studied by mixing $200 \mu \mathrm{L}$ ( $2 \mathrm{mmol}$ ) of 4-NP with $2 \mathrm{~mL}$ of deionized water in the cuvette and then adding $1 \mathrm{~mL}$ of $(0.03 \mathrm{M}) \mathrm{NaBH}_{4}$ to the mixture. The UV-visible spectra were measured at various times. The distance between the light source and the cuvette containing the mixture was kept constant at all 
times during the measurements. The same constituents were carried out again in the cuvette and $300 \mu \mathrm{L}$ of colloidal AgNPs were added. This was S1.Then, the UV-visible spectra were monitored at various time in situ using a UV-VIS spectrophotometer (Thermo-scientific Evolution 220). Samples S2 and S3 were used at the same volume (300 $\mu \mathrm{L})$ with fresh mixtures and the same concentrations of 4-NP and $\mathrm{NaBH}_{4}$. The S2 and S3 spectra were also measured at various times. To reduce thermal effects on the catalytic rate, the reaction temperature was held constant at room temperature $\left(20^{\circ} \mathrm{C}\right)$. The time until the reduction began and until it completed varied depending upon the size of the AgNPs.

\section{Results and Discussion}

\subsection{TEM Images of the AgNPs}

Figure 1(a)-(c) show TEM images of the AgNPs prepared under varying concentrations of trisodium citrate. The images show that all samples (S1, S2 and S3) are roughly spherical in shape and irregular in distribution. Nevertheless, some aggregation was observed in S3. The diameter of the nanoparticles was determined using a millimetre scale. The number of particles was counted within a bin of $5 \mathrm{~mm}$ [15]. As Figure 1(d)-(f) show, the average particle sizes were estimated at $9 \mathrm{~nm}, 11 \mathrm{~nm}$ and $14 \mathrm{~nm}$. These values indicate that the size of the particles increased with increasing trisodium citrate concentration. This may be because the higher concentration of trisodium increased the $\mathrm{pH}$ value of the solution, thus increasing the aggregation and particle size of the Ag ions.

\subsection{UV-VIS Spectra of AgNPs}

Figure 2 shows the absorption spectra of the AgNPs in the wavelength range of $350-700 \mathrm{~nm}$. A sharp peak is seen at the wavelengths; $388 \mathrm{~nm}, 390 \mathrm{~nm}$ and $400 \mathrm{~nm}$ for samples S1, S2 and S3, respectively. Due to the quantum size effect, the band shifted to higher wavelengths as the size of the nanoparticles increased. These bands are assigned to the surface plasmon bands that correspond to the completely or roughly spherical shape of the AgNPs. These bands express a collective oscillation frequency for the electrons in the conduction band. The electrons correlated to these sizes of AgNPs are much smaller than the incident wavelength. In this case, the electric field induced by light $\left(E_{o}\right)$ is constant and the electrons submit to the electromagnetic field and propagate like a plasmon wave [32]. Considering that the atoms' nuclei are still, the oscillation of the electrons leads

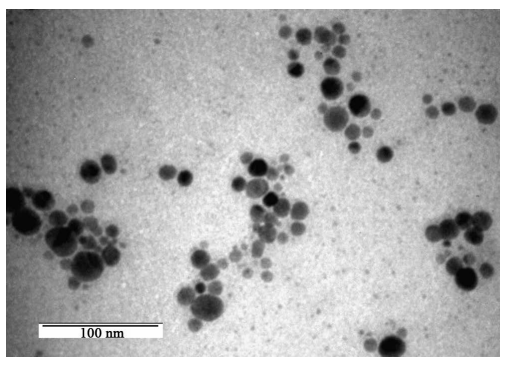

(a)

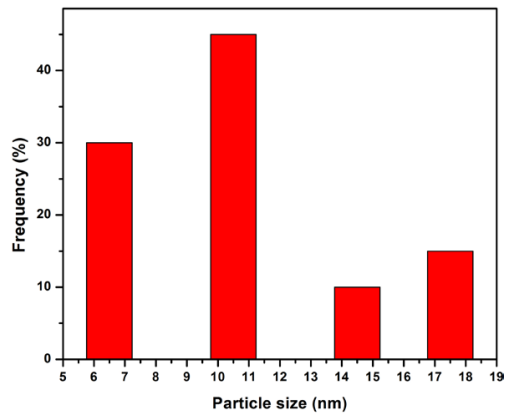

(d)

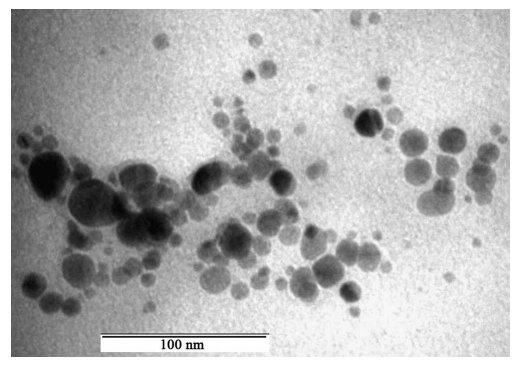

(b)

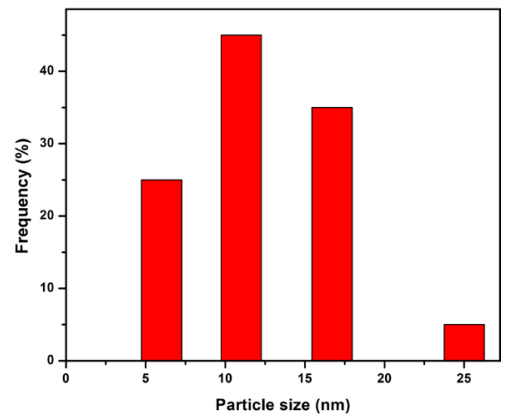

(e)

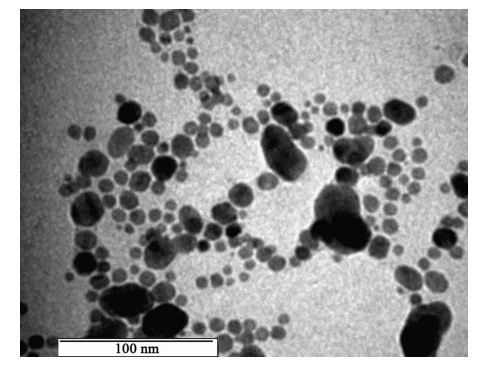

(c)

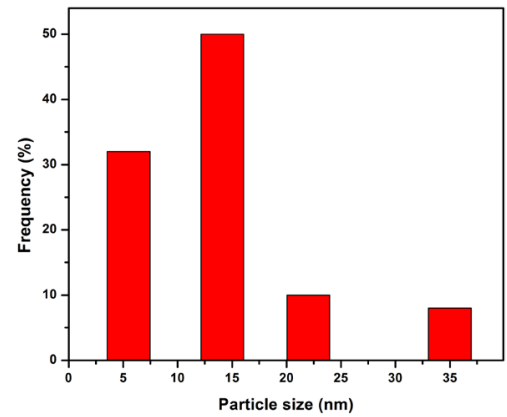

(f)

Figure 1. TEM images of AgNPs prepared with various concentrations of silver nitrate and trisodium citrate: sample S1 (20:5), S2 (20:20) and S3 (20:40). The average particle sizes estimated from the images were 9, 11 and 14 nm for samples S1, $\mathrm{S} 2$ and S3, respectively. 


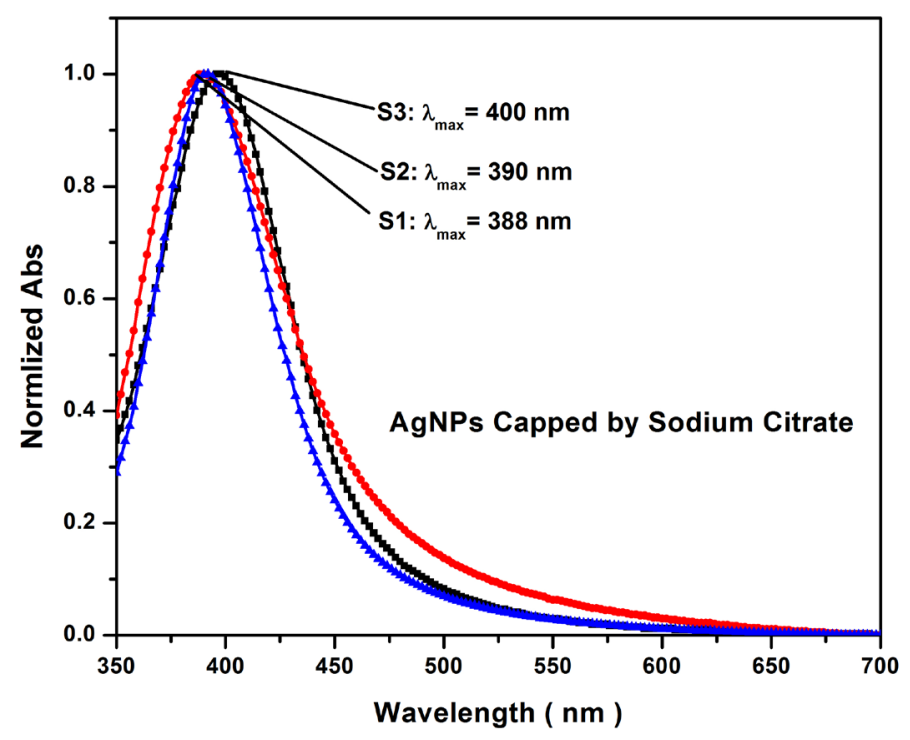

Figure 2. The UV-VIS absorption spectra for the colloidal AgNPs synthesized in various particle sizes: $9 \mathrm{~nm}$ (S1), $11 \mathrm{~nm}$ (S2) and $14 \mathrm{~nm}$ (S3).

to a periodic charge separation and generates oscillating dipoles whose magnitude reaches a maximum at the nanoparticles surface (Figure 3). At resonance, the amplitude of the local electric field in the particle, $E_{1}$, is enhanced compared to that of the applied field, $E_{0}$.

Figure 4 shows the UV-VIS spectra of the 4-NP $(2 \mathrm{mmol})$ with and without $\mathrm{NaBH}_{4}$. One band appeared at $317 \mathrm{~nm}$ in the 4-NP spectrum. This band is characterized as the electronic transition $\mathrm{n}-\pi^{*}$, owing to the lone pair of electrons (oxygen and nitrogen atoms) in the 4-NP structure. This peak shifted to a higher wavelength at 400 $\mathrm{nm}$ after the addition of $0.03 \mathrm{M}$ of $\mathrm{NaBH}_{4}$. The solution colour transformed from light yellow to yellow-green. This peak corresponds to the formation of 4-NP ions. This band decreased slightly with increased reduction time and became stable after 45 min without change. This result is in agreement with the previous work by Seoudi $e t$ al. [33] and Rashid et al. (2006) [34].

As shown in Figure 5, The catalytic activity of AgNPs of $9 \mathrm{~nm}$ (S1), $11 \mathrm{~nm}$ (S2) and $14 \mathrm{~nm}$ (S3) in diameter was analysed by measuring the UV-VIS spectrum of 4-NP in the range of $200-600 \mathrm{~nm}$ at various times in the presence of $\mathrm{NaBH}_{4}$.It is clear that the reduction in the band that appeared at $400 \mathrm{~nm}$ for each sample increased depending on the size of the nanoparticles. For S1, the band reduction was measured after 5 min. Usually, this time is ascribed to the diffusion time needed for adsorption of 4-NP onto the surface of the AgNPs. In addition, as mall, new band appeared at about $290 \mathrm{~nm}$. The decrease in the intensity of the band at $400 \mathrm{~nm}$ may be due to decreased 4-NP concentration, and the new band at $290 \mathrm{~nm}$ may be due to the formation of aminophenol (AP). The appearance of the latter can be explained as follows: $\mathrm{NaBH}_{4}$ reduces water to hydrogen as

$$
\mathrm{NaBH}_{4}+2 \mathrm{H}_{2} \mathrm{O} \rightarrow \mathrm{NaBO}_{2}+4 \mathrm{H}_{2}
$$

The reduction reaction was implemented by the hydrogen, and it involved the production of hydrogen gas, visible as bubbles. The decreased intensity of the peak at $400 \mathrm{~nm}$ was caused by the continuous consumption of 4-NP. The reaction mechanism was causative because the inherent hydrogen was adsorbed by AgNPs, which transported the hydrogen between the $\mathrm{NaBH}_{4}$ and the 4-NP. This behavior was expected because AgNPs adsorb hydrogen from the $\mathrm{NaBH}_{4}$ and efficiently release it through the reduction reaction; hence, AgNPs act as a hydrogen carrier in this reduction reaction. The same processes should have occurred during the reduction of 4-NP in the presence of $300 \mu \mathrm{L}$ of AgNPs in samples S2 and S3. In these samples, the absorption peak at $400 \mathrm{~nm}$ decreased with increasing time to complete reduction and a new, very low-intensity band (like a shoulder) appeared at about $290 \mathrm{~nm}$, indicating the formation of 4-AP but incomplete consumption of 4-NP. Furthermore, the intensity of this absorption band at $290 \mathrm{~nm}$ was very low. These data indicate that the 4-NP did not completely transform into 4-AP in samples S2 and S3. Figure 6 shows the mechanisms and forms of the reduction reactions for the transformation of 4-NP to 4-AP. The yellowcolourindicates4-NA, and colourless parts indicate the generation of 4-AP. 


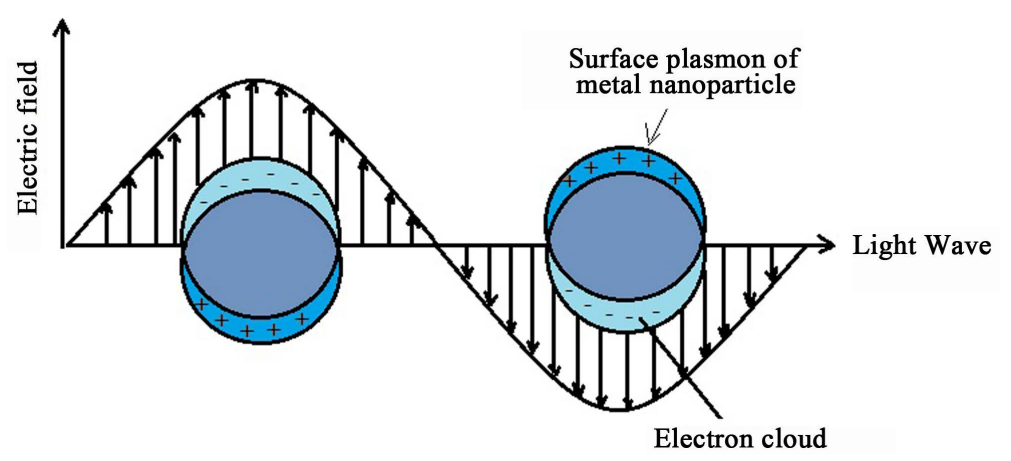

Figure 3. Oscillating dipoles induced by light radiation of the AgNPs.

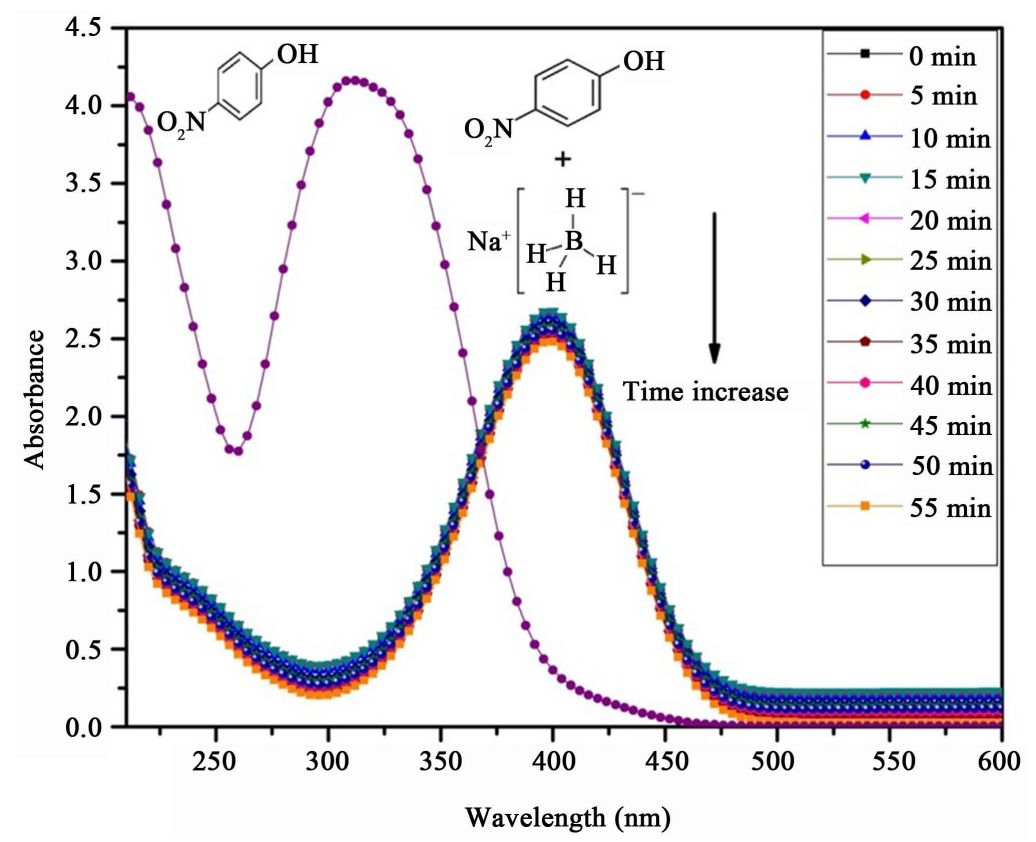

Figure 4. Measurements of the UV-VIS spectra of 4-NP over time with and without sodium borohydride.

Figure 7 shows the kinetic curves of the 4-NP reduction by AgNPs that are $9 \mathrm{~nm}$ (S1), $11 \mathrm{~nm}$ (S2) and $14 \mathrm{~nm}$ (S3) in diameter in the presence of $\mathrm{NaBH}_{4}$. The rate constant of the reaction was calculated from the decrease in intensity of the absorption peak at $400 \mathrm{~nm}$ overtime. A linear relation was observed between $\operatorname{Ln}\left(\mathrm{A} / \mathrm{A}_{0}\right)$ and time. As the concentration of sodium borohydride can be considered constant, the change in the ratio $\operatorname{Ln}\left(\mathrm{A} / \mathrm{A}_{\mathrm{o}}\right)$ with time corresponds to a first-order reaction kinetics equation, and the reaction can be directly calculated from the linear relation between $\operatorname{Ln}\left(\mathrm{A} / \mathrm{A}_{\mathrm{o}}\right)$ and time.

$$
\operatorname{Ln}\left(\mathrm{A} / \mathrm{A}_{\mathrm{o}}\right)=-\mathrm{k} \cdot \mathrm{t}
$$

where $A_{0}$ is the initial absorbance of the reaction system, $A$ is the absorbance at time $t$ and $k$ is the rate constant of the chemical reduction. From this kinetic curve, the rate constant $\left(\mathrm{k}, \mathrm{s}^{-1}\right)$ was calculated at $0.05 \mathrm{~s}^{-1}, 0.0015 \mathrm{~s}^{-1}$ and $0.00021 \mathrm{~s}^{-1}$ for the AgNPs of diameters $9 \mathrm{~nm}, 11 \mathrm{~nm}$ and $14 \mathrm{~nm}$, respectively. By comparing these rate constants of 4-NP in the presence of various sizes of AgNPs, it can be noted that S1, which contained 9-nm AgNPs, has more catalytic activity because AgNPs with higher particle sizes have lower interaction with4-NP. The reduction of 4-NP by S1 and S2 can be related to the Langmuir-Hinshelwood model of heterogeneous catalyzed reduction [35]. In this model, borohydride ions are adsorbed onto the surface of the nanoparticles, giving them the electrons. At the same time, molecules of 4-NP that are adsorbed onto the surface of the AgNPs lose electrons in the same proportion. After the reduction, the reaction product, 4AP, is desorbed from the silver surface. 


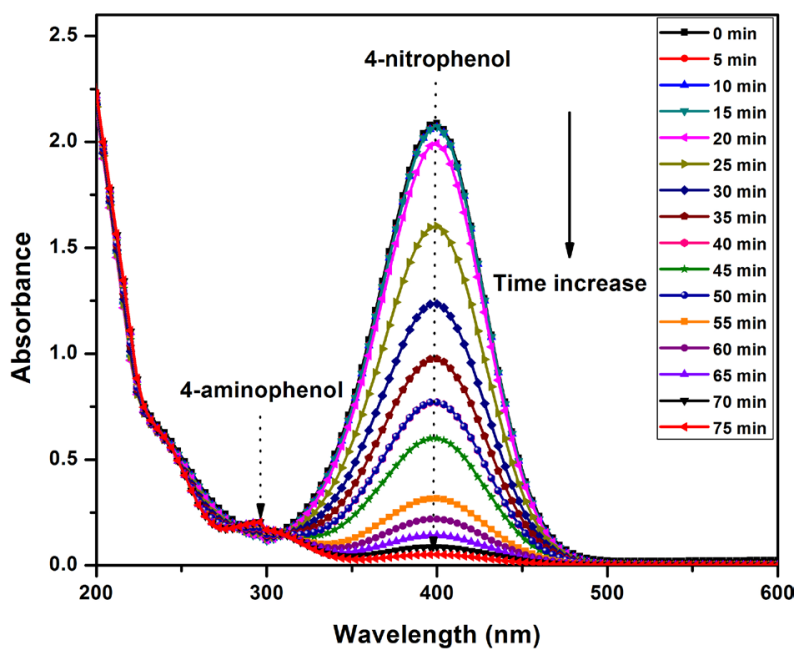

(a)

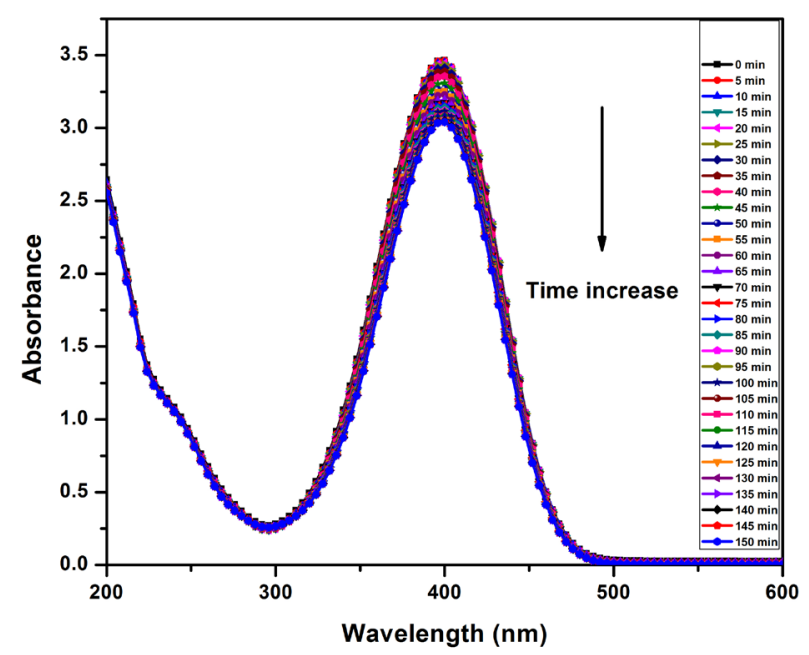

(b)

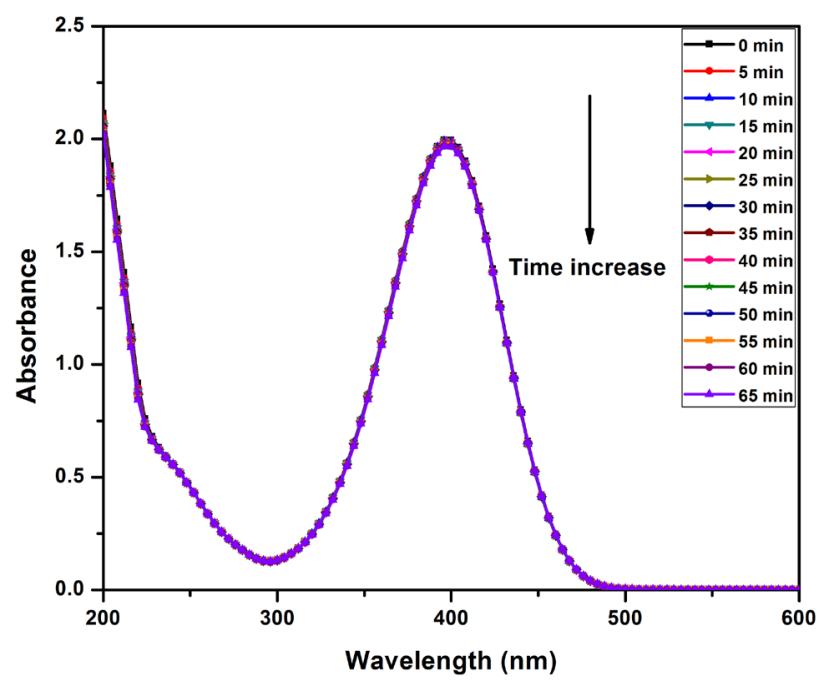

(c)

Figure 5. UV-VIS absorbance spectra for the reduction of 4-NP with $\mathrm{NaBH}_{4}$ in the presence of AgNPs with particle sizes of $9 \mathrm{~nm}$ (S1), $11 \mathrm{~nm}$ (S2) and $14 \mathrm{~nm}$ (S3). 

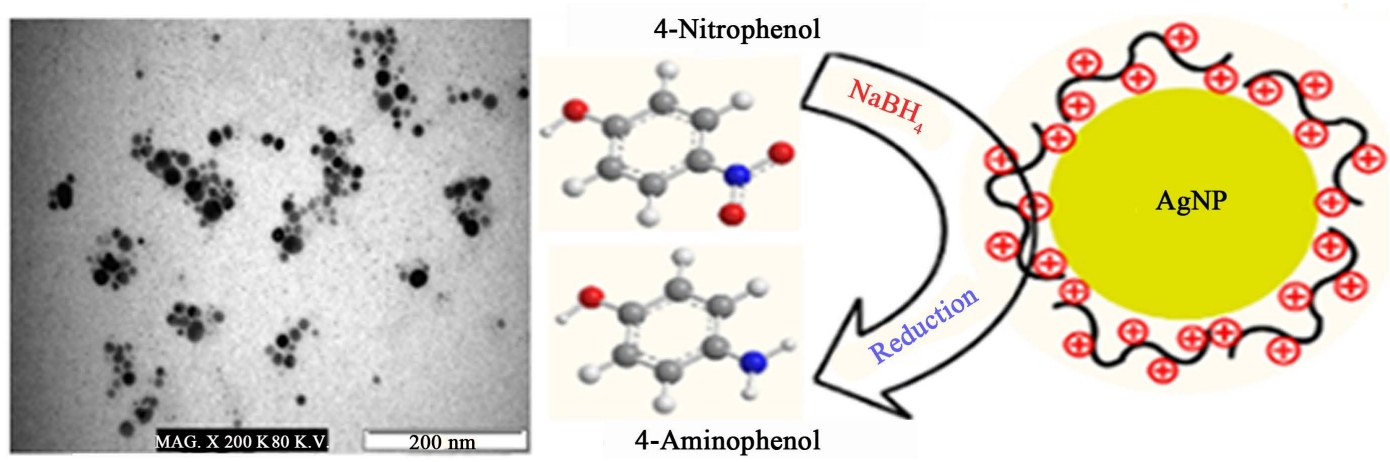

Figure 6. The mechanisms and forms of reduction reaction for 4-NP.
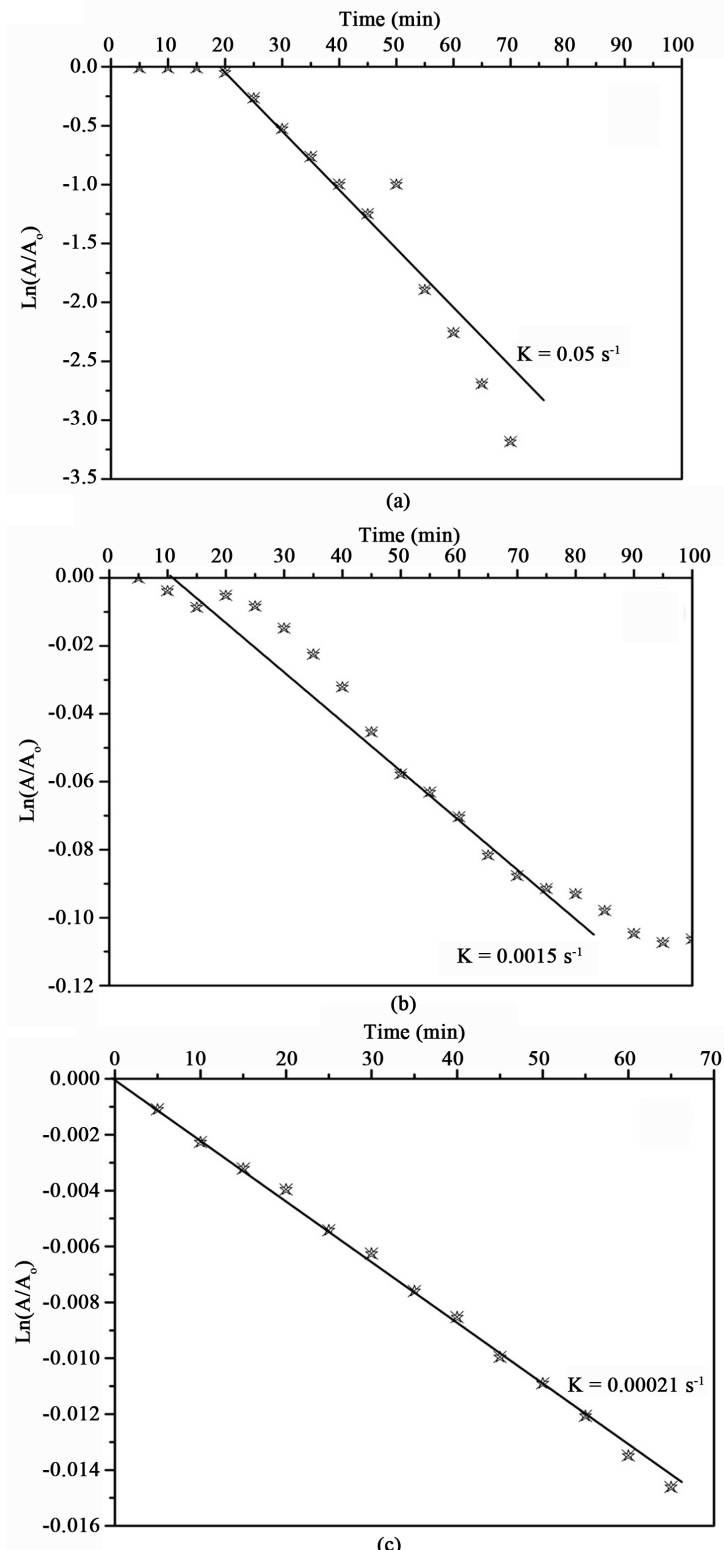

Figure 7. The kinetic curve of 4-NP reduction by AgNPs of (a) $9 \mathrm{~nm}$, (b) $11 \mathrm{~nm}$ and (c) $14 \mathrm{~nm}$ in diameter in the presence of $\mathrm{NaBH}_{4}$. 


\section{Conclusion}

AgNPs were synthesized in various sizes. The UV-VIS results show that the positions of the surface plasmonresonance bands depend on the size of the AgNP particles. In the prepared samples, AgNPs as a catalyst redactor transform the reduction of 4-NP to 4-AP. The smallest nanoparticles had the highest catalytic activity, and the rate constant of chemical reduction decreased with increasing size of the AgNP particles.

\section{References}

[1] Al-Taa’y, W., Nabi, M.A., Yusop, R.M., Yousif, E., Abdullah, B.M., Salimon, J., Salih, N. and Zubairi, S.I. (2014) Effect of Nano ZnO on the Optical Properties of Poly(vinyl chloride) Films. International Journal of Polymer Science, 2014, Article ID: 697809. http://dx.doi.org/10.1155/2014/697809

[2] Ahmadpoor, P., Nateri, A.S. and Motaghitalab, V. (2013) The Optical Properties of PVA/TiO 2 Composite Nanofibers. Applied Polymer Science, 130, 78-85. http://dx.doi.org/10.1002/app.39147

[3] Yang, W., Xie, T., Jiang, T. and Wang, D. (2013) Facile Preparation of $\mathrm{Ag}_{2} \mathrm{~S}$ Nanoparticles with Broad Photoelectric Response Region. Colloids and Surfaces A: Physicochemical and Engineering Aspects, 433, 55-58. http://dx.doi.org/10.1016/j.colsurfa.2013.05.007

[4] Pristinski, D., Tan, S., Erol, M., Du, H. and Sukhishvili, S. (2006) In Situ SERS Study of Rhodamine 6G Adsorbed on Individually Immobilized Ag Nanoparticles. Raman Spectroscopy, 37, 762-770. http://dx.doi.org/10.1002/jrs.1496

[5] Lv, Y., Li, K. and Li, Y. (2013) Surface Modification of Quantum Dots and Magnetic Nanoparticles with PEG-Conjugated Chitosan Derivatives for Biological Applications. Chemical Papers, 67, 1404-1413. http://dx.doi.org/10.2478/s11696-013-0401-1

[6] Kusior, A., Klich-Kafel, J., Trenczek-Zajac, A., Swierczek, K., Radecka, M. and Zakrzewska, K. (2013) $\mathrm{TiO}_{2}-\mathrm{SnO}_{2}$ Nanomaterials for Gas Sensing and Photocatalysis. Journal of the European Ceramic Society, 33, 2285-2290. http://dx.doi.org/10.1016/j.jeurceramsoc.2013.01.022

[7] Son, H., Ko, G. and Zoh, K. (2009) Kinetics and Mechanism of Photolysis and $\mathrm{TiO}_{2}$ Photocatalysis of Triclosan. Journal of Hazardous Materials, 166, 954-960. http://dx.doi.org/10.1016/j.jhazmat.2008.11.107

[8] Bhui, D., Bar, H., Sarkar, P., Sahoo, G., De, S. and Misra, A. (2009) Synthesis and UV-VIS Spectroscopic Study of Silver Nanoparticles in Aqueous SDS Solution. Journal of Molecular Liquids, 145, 33-37. http://dx.doi.org/10.1016/j.molliq.2008.11.014

[9] Stamplecoskie, K., Scaiano, J., Tiwari, V. and Anis, H. (2011) Optimal Size of Silver Nanoparticles for Surface-Enhanced Raman Spectroscopy. The Journal of Physical Chemistry C, 115, 1403-1409. http://dx.doi.org/10.1021/jp106666t

[10] Kim, D., Jeong, S. and Moon, J. (2006) Synthesis of Silver Nanoparticles Using the Polyol Process and the Influence of Precursor Injection. Nanotechnology, 17, 4019-4024. http://dx.doi.org/10.1088/0957-4484/17/16/004

[11] Zhang, R., Moon, K.S., Lin, W. and Wong, C.P. (2010) Preparation of Highly Conductive Polymer Nanocomposites by Low Temperature Sintering of Silver Nanoparticles. Journal of Materials Chemistry, 20, 2018-2023. http://dx.doi.org/10.1039/b921072e

[12] Xiong, Y., Siekkinen, A.R., Wang, J., Yin, Y., Kimb, M.J. and Xia, Y. (2007) Synthesis of Silver Nanoplates at High Yields by Slowing Down the Polyol Reduction of Silver Nitrate with Polyacrylamide. Journal of Materials Chemistry, 17, 2600-2602. http://dx.doi.org/10.1039/b705253g

[13] Thompson, D.G., Stokes, R.J., Martin, R.W., Lundahl, P.J., Faulds, K. and Graham, D. (2008) Synthesis of Unique Nanostructures with Novel Optical Properties Using Oligonucleotide Mixed-Metal Nanoparticle Conjugates. Small, 4, 1054-1057. http://dx.doi.org/10.1002/smll.200700938

[14] Pradhan, N., Pal, A. and Pal, T. (2002) Silver Nanoparticle Catalyzed Reduction of Aromatic Nitro Compounds. Colloids and Surfaces A: Physicochemical and Engineering Aspects, 196, 247-257. http://dx.doi.org/10.1016/S0927-7757(01)01040-8

[15] Soliman, M.S., Seoudi, R. and Shabaka, A.A. (2005) Polymer Based Films Embedded with High Content of ZnSe Nanoparticles. Materials Letters, 59, 2650-2654. http://dx.doi.org/10.1016/j.matlet.2005.04.012

[16] Takenobu, T., Miura, N., Lu, S.Y., Okimoto, H., Asano, T., Shiraishi, M. and Iwasa, Y. (2009) Ink-Jet Printing of Carbon Nanotube Thin-Film Transistors on Flexible Plastic Substrates. Applied Physics Express, 2, 0250051-0250053. http://dx.doi.org/10.1143/APEX.2.025005

[17] Jung, J., Oh, H., Noh, H., Ji, J. and Kim, S. (2006) Metal Nanoparticle Generation Using a Small Ceramic Heater with a Local Heating Area. Journal of Aerosol Science, 37, 1662-1670. http://dx.doi.org/10.1016/j.jaerosci.2006.09.002

[18] Sylvestre, J.P., Kabashin, A.V., Sacher, E., Meunier, M. and Luong, J. (2004) Stabilization and Size Control of Gold 
Nanoparticles during Laser Ablation in Aqueous Cyclodextrins. Journal of the American Chemical Society, 126, 71767177. http://dx.doi.org/10.1021/ja048678s

[19] Zhang, W., Qiao, X. and Chen, J. (2007) Synthesis of Nanosilver Colloidal Particles in Water/Oil Microemulsion. Colloids and Surfaces A: Physicochemical and Engineering Aspects, 299, 22-28. http://dx.doi.org/10.1016/j.colsurfa.2006.11.012

[20] Zhou, Y., Yu, S.H., Wang C., Li, X., Zhu, Y. and Chen, Z. (1999) A Novel Ultraviolet Irradiation Photoreduction Technique for the Preparation of Single-Crystal Ag Naorods and Ag Dendrites. Advanced Materials, 11, 850-852. http://dx.doi.org/10.1002/(SICI)1521-4095(199907)11:10<850::AID-ADMA850>3.0.CO;2-Z

[21] Shchukin, D., Radtchenko, I. and Sukhorukov, G. (2003) Photoinduced Reduction of Silver inside Microscale Polyelectrolyte Capsules. Physical Chemistry and Chemical Physics, 4, 1101-1103.

[22] Ma, H., Yin, B., Wang, S., Jiao, Y., Pan, W. and Huang, S. (2004) Synthesis of Silver and Gold Nanoparticles by a Novel Electrochemical Method. Physical Chemistry and Chemical Physics, 24, 68-75.

[23] Eutis, S., Krylova, G., Eremenko, A., Smirnova, N., Schill, A.W. and El-Sayed, M. (2005) Growth and Fragmentation of Silver Nanoparticles in Their Synthesis with a fs Laser and CW Light by Photo-Sensitization with Benzophenone. Photochemical \& Photobiological Sciences, 4,154-159. http://dx.doi.org/10.1039/b411488d

[24] Nadagouda, M., Speth, T. and Varma, R. (2011) Microwave-Assisted Green Synthesis of Silver Nanostructures. Accounts of Chemical Research, 44, 469-478. http://dx.doi.org/10.1021/ar1001457

[25] Kalishwaralal, K., Deepak, V., Ramkumarpandian, S., Nellaiah, H. and Sangiliyandi, G. (2008) Extracellular Biosynthesis of Silver Nanoparticles by the Culture Supernatant of Bacillus Licheniformis. Materials Letters, 62, 4411-4413. http://dx.doi.org/10.1016/j.matlet.2008.06.051

[26] Kalishwaralal, K., Deepak, V., Ramkumarpandian, S., Bilal, M. and Gurunathan, S. (2008) Biosynthesis of Silver Nanocrystals by Bacillus Licheniformis. Colloids and Surfaces B: Biointerfaces, 65, 150-153. http://dx.doi.org/10.1016/j.colsurfb.2008.02.018

[27] Chakraborty, N., Banerjee, A., Lahiri, S., Panda, A., Ghosh, A.N. and Pal, R. (2009) Biorecovery of Gold Using Cyanobacteria and an Eukaryotic Alga with Special Reference to Nanogold Formation-A Novel Phenomenon. Journal of Applied Phycology, 21, 145-152. http://dx.doi.org/10.1007/s10811-008-9343-3

[28] Krishnaraj, C., Jagan, E., Rajasekar, S., Selvakumar, P., Kalaichelvan, P. and Mohan, N. (2010) Synthesis of Silver Nanoparticles Using Acalypha indica Leaf Extracts and Its Antibacterial Activity against Water Borne Pathogens. Colloids and Surfaces B: Biointerfaces, 76, 50-56. http://dx.doi.org/10.1016/j.colsurfb.2009.10.008

[29] Prasad, T. and Elumalai, E. (2011) Biofabrication of Ag Nanoparticles Using Moringa oleifera Leaf Extract and Their Antimicrobial Activity. Asian Pacific Journal of Tropical Biomedicine, 1, 439-442. http://dx.doi.org/10.1016/S2221-1691(11)60096-8

[30] Lai, T.-L., Yong, K.-F., Yu, J.-W., Chen, J.H., Shu, Y.-Y. and Wang, C.-B. (2011) High Efficiency Degradation of 4-Nitrophenol by Microwave-Enhanced Catalytic Method. Journal of Hazardous Materials, 185, 366-372. http://dx.doi.org/10.1016/j.jhazmat.2010.09.044

[31] Li, J.H., Kuang, D.Z., Feng, Y.L., Zhang, F.X., Xu, Z.F. and Liu, M.Q. (2012) A Graphene Oxide-Based Electrochemical Sensor for Sensitive Determination of 4-Nitrophenol. Journal of Hazardous Materials, 201-202, 250-259. http://dx.doi.org/10.1016/j.jhazmat.2011.11.076

[32] Seoudi, R., Fouda, A. and Elmenshawy, A. (2010) Synthesis, Characterization and Vibrational Spectroscopic Studies of Different Particle Size of Gold Nanoparticle Capped with Polyvinylpyrrolidone. Physica B, 405, 906-911. http://dx.doi.org/10.1016/j.physb.2009.10.012

[33] Seoudi, R. and Said, D. (2011) Studies on the Effect of the Capping Materials on the Spherical Gold Nanoparticles Catalytic Activity. World Journal of Nano Science and Engineering, 1, 51-61.

http://dx.doi.org/10.4236/wjnse.2011.12008

[34] Rashid, M., Bhattacharjee, R., Kotal, A. and Mandal, T. (2006) Synthesis of Spongy Gold Nanocrystals with Pronounced Catalytic Activities. Langmuir, 22, 7141-7143. http://dx.doi.org/10.1021/la060939j

[35] Khalavka, Y., Becker, J. and Soennichsen, C. (2009) Synthesis of Rod-Shaped Gold Nanorattles with Improved Plasmon Sensitivity and Catalytic Activity. Journal of the American Chemical Society, 131, 1871-1875. http://dx.doi.org/10.1021/ja806766w 